\title{
Rare source of catecholamine secretion in two cases
}

\author{
Y Khalid, E Chinnasamy, G Bano
}

St George's University Hospital, London, NHS Foundation Trust

\section{Introduction}

Pheochromocytomas account for increased catecholamine secretion in about $90 \%$ of cases. Less than $5 \%$ of head and neck paragangliomas (PGs) secrete catecholamines ${ }^{1}$

As in all extra-adrenal catecholamine secreting paragangliomas they produce predominantly norepinephrine and little epinephrine secretion. About $25 \%$ of PGs are familial and have mutations involving RET,VHL, SDHB, SDHC or SDHD and other genes ${ }^{2}$.

We present two cases of carotid body tumours (CBT) with systemic manifestations and increased catecholamine secretion.

\section{Case 1}

A 44 year old gentleman presented with dizziness, headache, facial flushing and blackouts while coughing. He had no significant past medical history and he was not on any medications. There was no family history of note.

On examination his BP was $139 / 87 \mathrm{mmHg}$, Pulse rate $96 / \mathrm{min}$

He had a large $6 \mathrm{~cm}$ firm, non-tender swelling on the right side of neck.

No palpable lymphadenopathy, thyroid gland was not enlarged.

Neurological examination unremarkable.

Plasma Metanephrine Result

\begin{tabular}{l|c|c|}
\hline & Result & Normal range \\
\hline Metadrenaline & $165.1 \mathrm{pmol} / \mathrm{L}$ & $<510 \mathrm{pmol} / \mathrm{L}$ \\
\hline Normetadrenaline & $1736 \mathrm{pmol} / \mathrm{L}$ & $<1180 \mathrm{pmol} / \mathrm{L}$ \\
\hline 3-Methoxytyramine & $290.4 \mathrm{pmol} / \mathrm{L}$ & $<180 \mathrm{pmol} / \mathrm{L}$ \\
\hline
\end{tabular}

Carotid duplex scan showed $4.5 \mathrm{~cm}$ mass in the Right anterior triangle with organised vascularisation.

MRI of Neck thorax and abdomen showed a $4.0 \times 2.2 \times 6.2 \mathrm{~cm}$ contrast enhancing lesion between the internal and external carotid artery. This lesion was MIBG and Octreotide avid. The adrenal glands were normal.

\section{MRI scan}

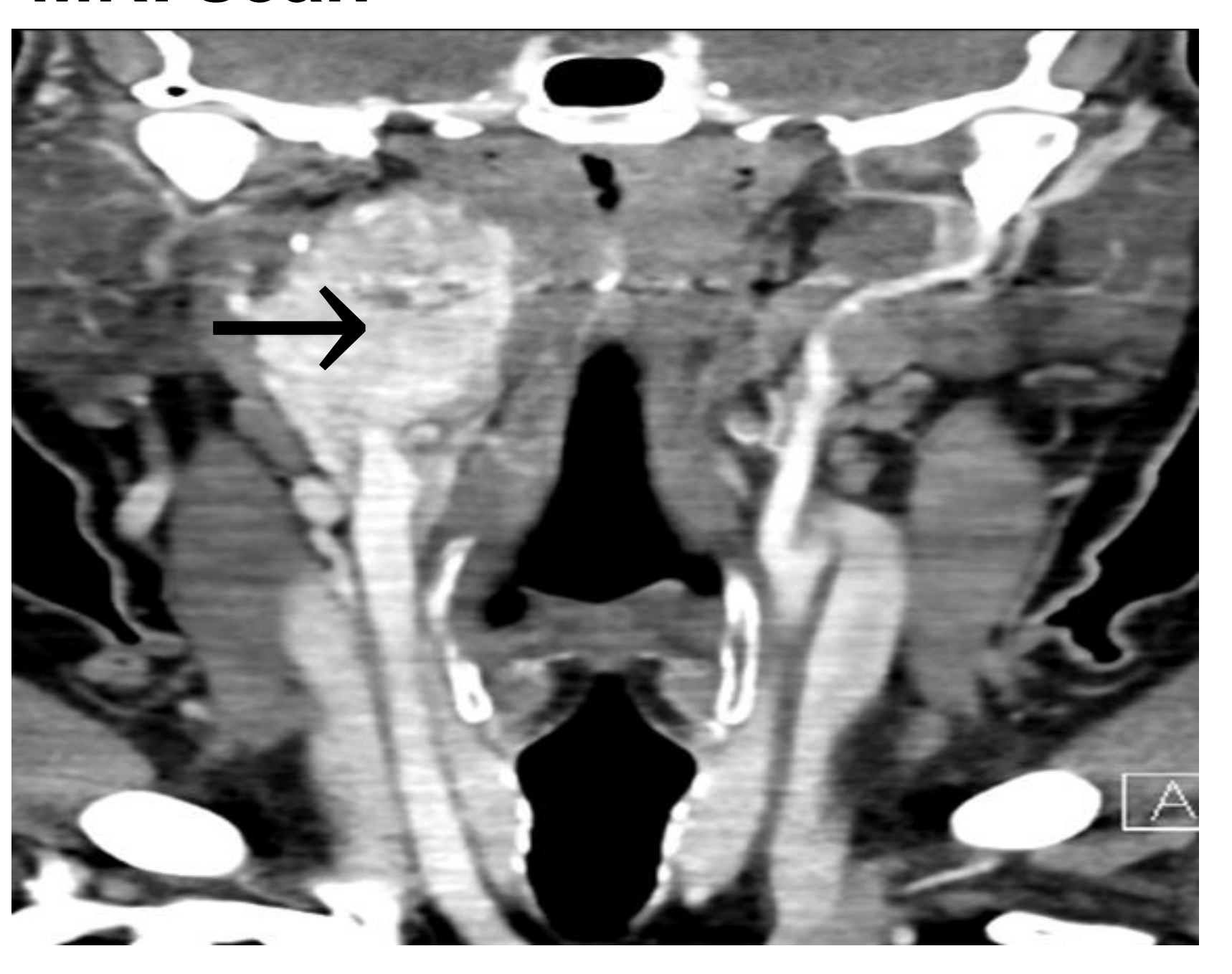

\section{Octreotide scan}

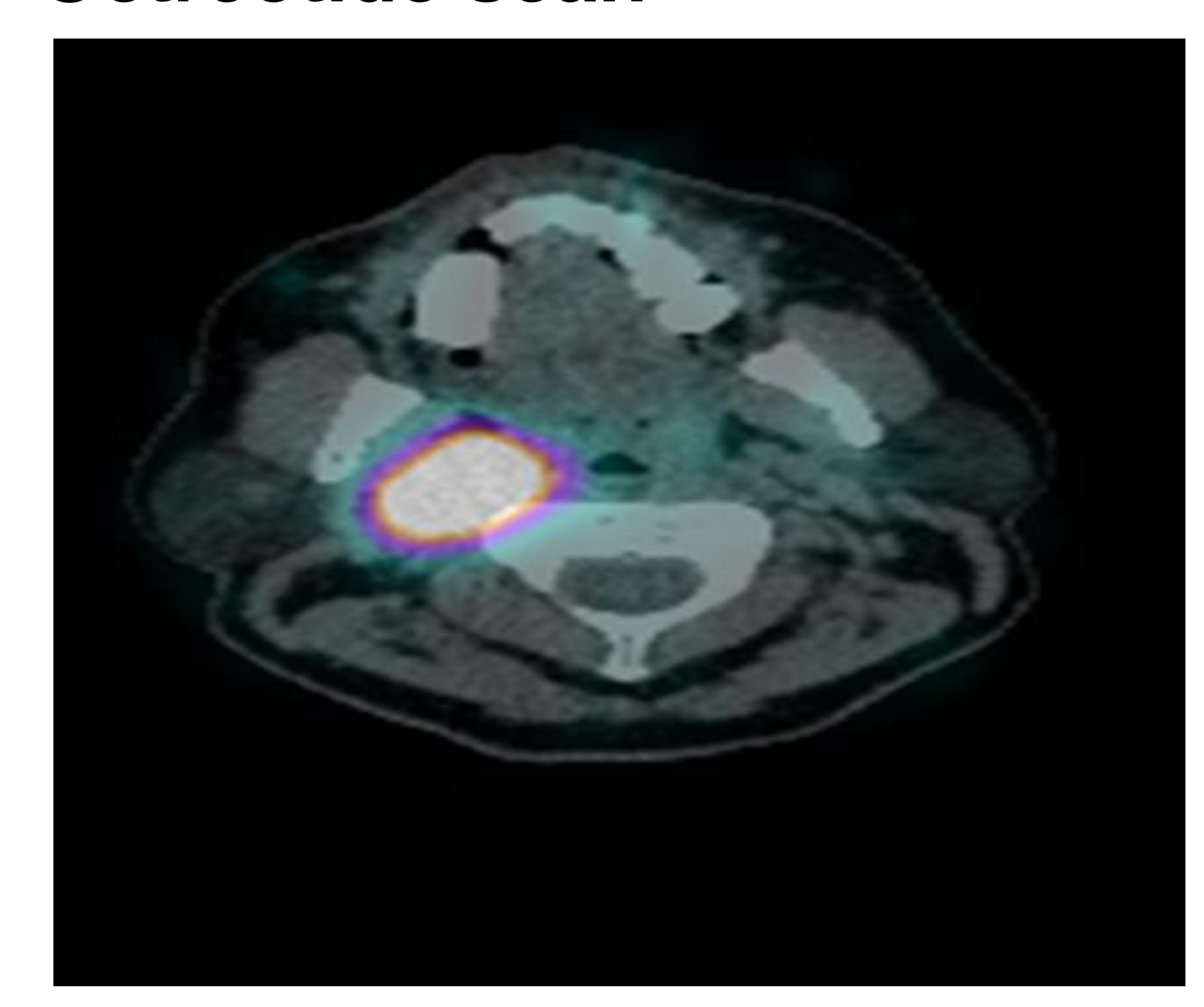

Genetic tests confirmed that he had SDHB mutation. He was referred to the head and neck MDT and because of the morbidity associated with surgery, including damage to the adjacent nerves, after a discussion with the patient a plan was made to manage him conservatively. His symptoms settled after being commenced on phenoxybenzamine. He remains under regular endocrine follow up.

\section{Case 2}

A 43 year old Caucasian lady was referred with 11 months history of $>$ light headedness

$>$ pre-syncope usually when lying flat or on extension of her neck

$>$ transient loss of consciousness

Family History: mother had renal cell carcinoma

She had no past medical history of note, and was not on any medications

On examination her BP $110 / 70 \mathrm{mmHg}$, pulse rate $98 / \mathrm{min}$

-A right level 2 neck mass $3 \mathrm{~cm}$ with a smaller left level 2 neck mass - No palpable lymphadenopathy, thyroid not enlarged and neurological examination unremarkable

24 Hour urine for Metanephrine Result (Urine Volume 1.4 L)

\begin{tabular}{l|c|c|} 
& \multicolumn{1}{c}{ Result } & Normal range \\
\hline Metadrenaline & $2.14 \mathrm{umol}$ & 0 to $1.20 \mathrm{umol}$ \\
\hline Normetadrenaline & $5.21 \mathrm{umol}$ & 0 to $3.30 \mathrm{umol}$ \\
\hline 3-Methoxytyramine & $5.03 \mathrm{umol}$ & 0 to $2.50 \mathrm{umol}$ \\
\hline
\end{tabular}

Duplex scan showed bilateral carotid body tumours, the right measuring $3.2 \mathrm{~cm}$ and left $1.6 \mathrm{~cm}$. Both were FDG PET avid, while the Right was MIBG avid.
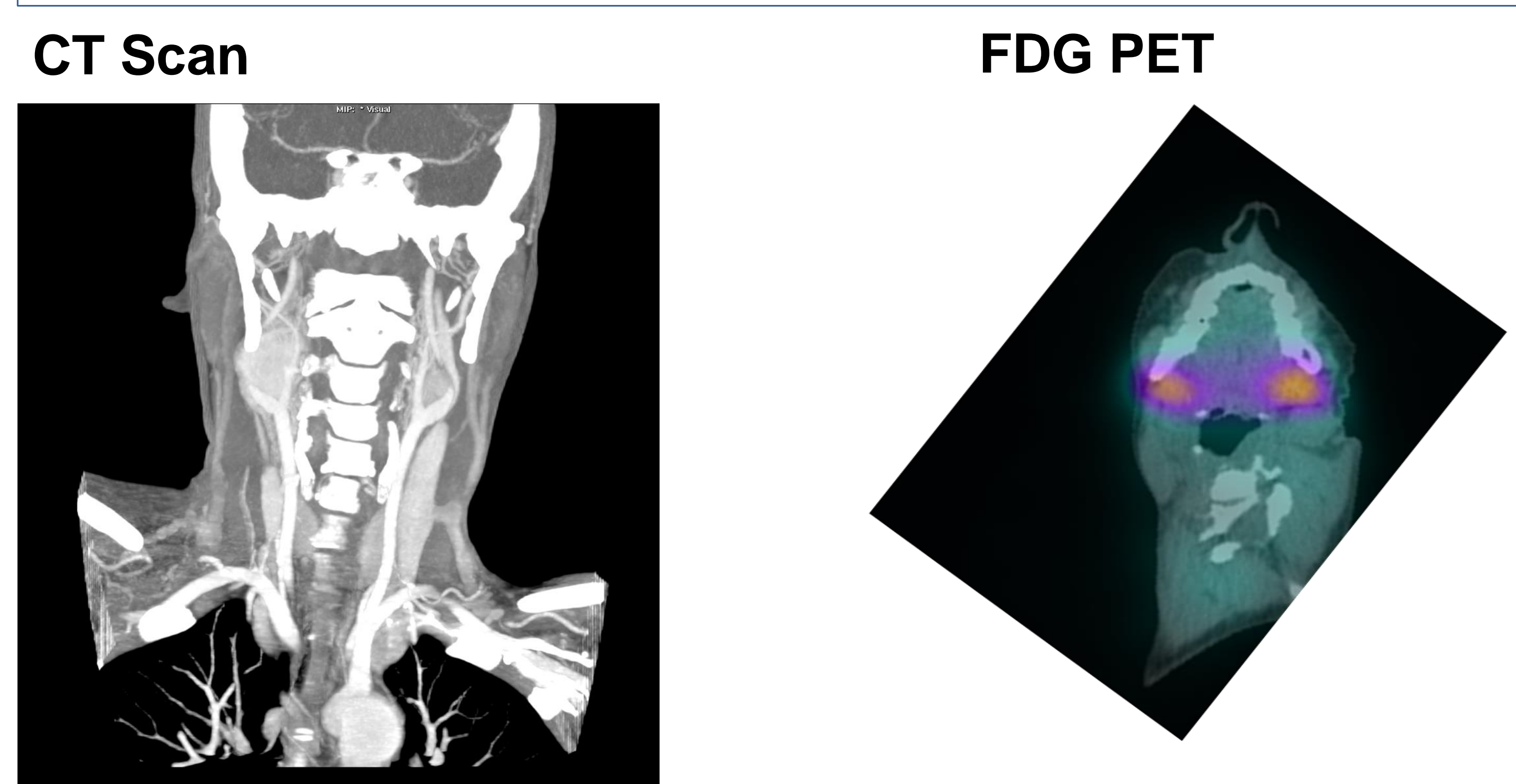

Following commencement of alpha and later beta blockers, she underwent surgery and the right carotid body tumour was removed. Post-operatively she remains well and we are awaiting the results of repeat urine metanephrine levels.

DisCUSSion
Secretory paragangliomas are very rare. As these tumours are extra-adrenal,
they may have elevated levels of normetadrenaline and 3 methoxytyramine, the
latter is produced by the breakdown of dopamine via COMT enzyme. The tumour
may be localised by MIBG scan. The MIBG molecule resembles norepinephrine
and is taken up preferentially by adrenergic tissue. Although MIBG scan is specific
(100\%), it has a low sensitivity (41.6-60\%) in mapping metastatic
paragangliomas. Gadolinium-68-DOTA-octreotate (68Ga-DOTATATE) (PET)/CT
scanning has been shown to have higher diagnostic accuracy and sensitivity in
mapping paraganglioma metastases.
The management of these patients requires team work between the
endocrinologist, surgeon and anaesthetist. It is important to ensure patients are
adequately alpha blocked and later beta blocked prior to surgery to prevent
hypertensive crisis during surgery.

\section{References}

Elshafie, O Al Badaai et al N (2014). Catecholamine-secreting carotid body paraganglioma: successfu preoperative control of hypertension and clinical symptoms using high-dose long-acting octreotide. Endocrinology Diabetes \& Metabolism Case Reports, 2014

Lefebvre, M., \& Foulkes, W. D. (2014). Pheochromocytoma and paraganglioma syndromes: genetics and management update. Current Oncology,fEB 